\title{
Modeling Nutrient and PlankTon Processes in the California Coastal Transition Zone
}

\author{
By John R. Moisan
}

$T_{1}$ HE CALIFORNIA COASTAL TRANSITION ZONE (CTZ) is a region of the North American eastern boundary current system which is associated with cold, nutrient- and pigment-rich filaments that originate near the coast and can extend offshore as much as $300 \mathrm{~km}$. On the basis of recent programs, it is now known that these filaments develop and decay over a period of a few weeks, occur most frequently during the spring and summer (Strub et al., 1991), and are associated with capes and upwelling regions. These filaments are about $50 \mathrm{~km}$ wide at peak development and show considerable curvature and meandering. The maximum horizontal velocities within these filaments have been measured in excess of $50 \mathrm{~cm} \mathrm{~s}^{-1}$ and support a volume transport of 2-6 Sv $\left(1 \mathrm{~Sv}=1.0 \times 10^{6} \mathrm{~m}^{3} \mathrm{~s}^{-1}\right)$. As a result, these features are of considerable interest as they may be an important mechanism for the across-shore flux of carbon and nutrients. Little is known about the relative contribution of carbon export from coastal regions to the open ocean to the overall global carbon cycle.

The focus of my dissertation was to incorporate a food web model of the CTZ into a three-dimensional circulation model that was capable of reproducing the circulation patterns (i.e., filaments) observed in the CTZ and to use this model as a tool to investigate the interactions associated with such a highly dynamic coastal phenomenon (Moisan, 1993). The biological portion of the model consisted of a nine-component food web that included silicate, nitrate, ammonium, two phytoplankton size fractions, three zooplankton categories (copepod, euphausiid, and doliolid) and a

J.R. Moisan, Physical Oceanography Research Division, Scripps Institute of Oceanography, 9500 Gilman Drive, La Jolla, California, 92093-0230, USA; Ph.D. 1993, Center for Coastal Physical Oceanography. Old Dominion University, Norfolk, Virginia (advisor: E.E. Hofmann). detrital pool. Transfers within the food web occurred through nutrient uptake by phytoplankton, differential grazing by zooplankton, and nutrient recycling. Coupled to the food web model was a modified version of the subsurface spectral $(400-700 \mathrm{~nm})$ irradiance model of Sathyendranath and Platt (1988). This bio-optical model was then coupled to the three-dimensional, primitive equation circulation model that was developed for the CTZ region (Haidvogel et al., 1991a,b). The three-dimensional circulation model provided the velocities and kinematic eddy diffusivities that were used to advect and diffuse the components of the biological model.

The focus of this article is to present the results of the model in the context of the resulting biological fields and their associated across-shore carbon flux estimates. The large-scale horizontal structure of the simulated flow field from day 150 (Fig. 1A) showed an emerging filament, which had elongated and extended offshore about $430 \mathrm{~km}$. The filaments observed within the CTZ typically extend offshore more than $300 \mathrm{~km}$ and have widths of $\approx 75 \mathrm{~km}$. Maximum horizontal velocities, as indicated by the sharp density gradients (cf. Fig. 1A), within the simulated filament $(0.8$ to $1 \mathrm{~m}$ $\mathrm{s}^{-1}$ ) were similar to those observed in the CTZ field data, $0.8 \mathrm{~m} \mathrm{~s}^{-1}$. The general across-shore simulated phytoplankton distributions (Fig. 1B) are similar to those observed within the CTZ. Phytoplankton concentrations, integrated over the depth of the euphotic zone ( $1 \%$ photosynthetically available radiation, PAR), showed that the highest concentrations occur along the coast and along the axis of the filament where horizontal velocities are lowest (e.g., $>1 \mathrm{mg}-\mathrm{chl} a \mathrm{~m}^{-3}$ ) and decreased rapidly (e.g., $<0.1 \mathrm{mg}-\mathrm{chl} a \mathrm{~m}^{-3}$ ) across the density front. The euphotic zone depth (cf. Fig. 1B) was shallowest $(\approx 40 \mathrm{~m})$ along the coastal regions and within the filament, which coincided with the regions of highest chlorophyll concentration. Sharp gradients in both the phytoplankton concentrations and the depth of the euphotic zone occurred in the coastal region and along the northern and southern sides of the filament. The gradient was stronger on the southern side of the filament where upwelling velocities occurred (cf. Fig. I, A and B).

The model across-shore carbon flux estimates showed that the filament contained regions of high onshore and offshore carbon flux of essentially equal magnitudes (Fig. 1, C and D). The regions of largest offshore and onshore flux were not associated with regions of high phytoplankton concentrations (cf. Fig. 1C) but rather with regions of high across-shore velocities (cf. Fig. 1D). The simulated surface carbon flux field suggested that there are specific regions within the filament that are responsible for the majority of the across-shore flux of carbon. The highest offshore (onshore) surface carbon flux (e.g., $>21$ (12)

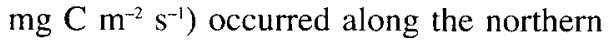
(southern) flank of the filament, coincident with the region of highest offshore (onshore) velocities. A higher offshore than onshore surface flux was attributed to the effect of the velocities associated with filament elongation. An estimate of the total annual cross-shore carbon transport was obtained from these flux estimates. Filaments are generated within the CTZ from May to October for a total of about 3-6 mo and have a lifetime of about $1 \mathrm{mo}$. Also, as many as 1-6 filaments have been observed in various stages of development along the western coast of the United States. Using these estimates, the filaments along the California coast can transport between 158 and $1890 \mathrm{~g} \mathrm{C} \mathrm{m}^{-2} \mathrm{y}^{-1}$ as much as $500 \mathrm{~km}$ offshore. This large offshore transport of carbon may supply the food required to support the high zooplankton bio- 


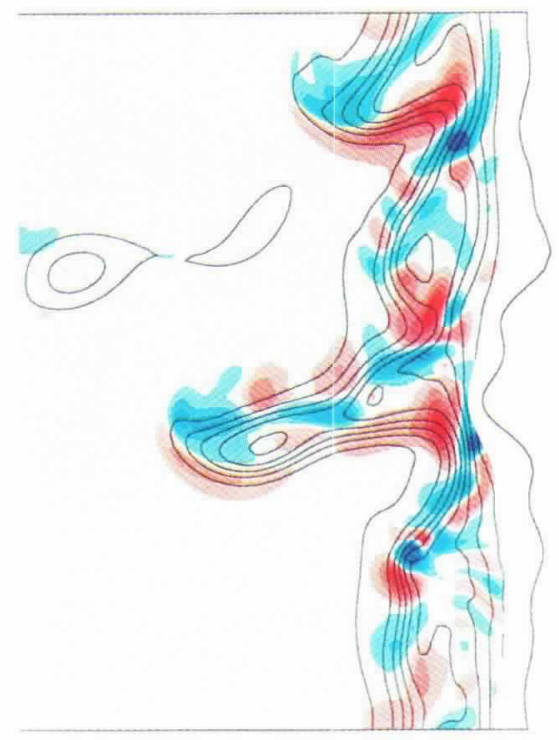

(A)

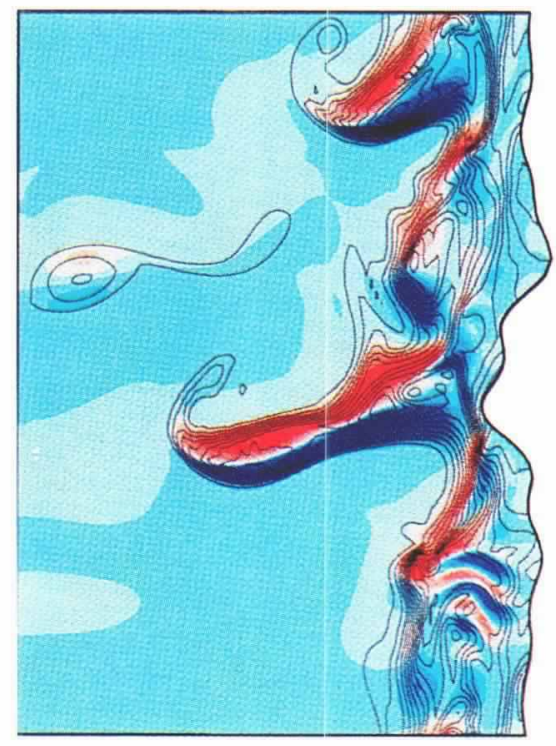

(C)

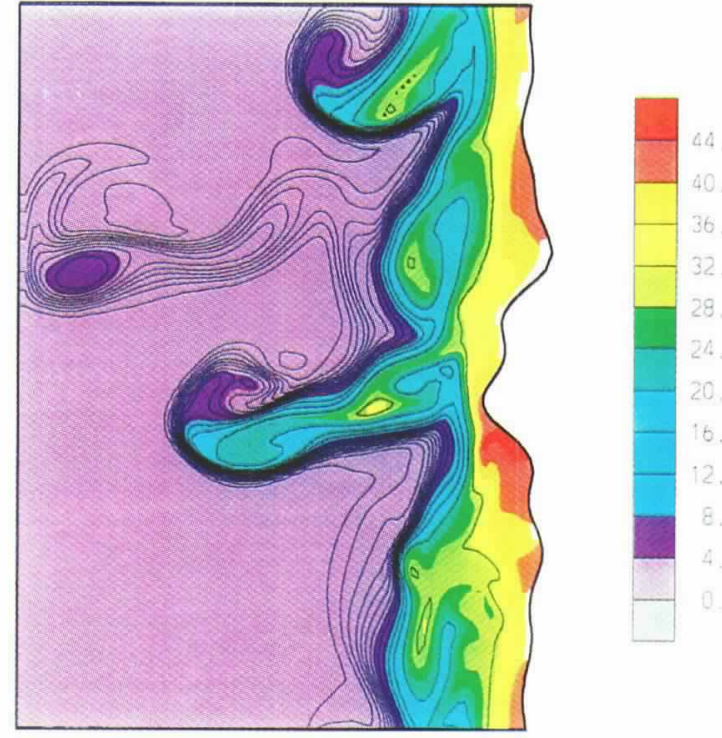

(B)

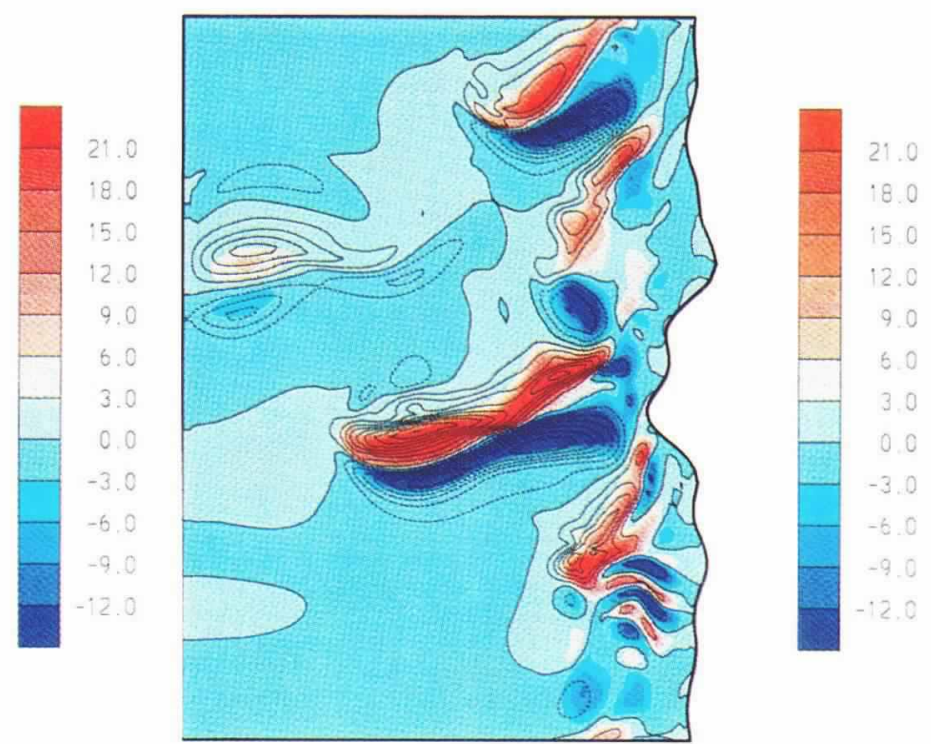

(D)

Fig. 1: Horizontal distribution of the $(\boldsymbol{A})$ vertical velocity (color; $\mathrm{m} \mathrm{s}^{-1}$ ) and density (line contours; $\left.\sigma_{t}\right)$ at $100 \mathrm{~m}$ depth, $(\boldsymbol{B})$ phytoplank-

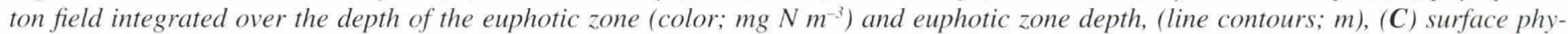
toplankton carbon flux field (color; $\mathrm{mg} \mathrm{C} \mathrm{m}^{-2} \mathrm{~s}^{-1}$ ), and surface phytoplankton carbon field (line contours; $\left.\mathrm{mg} C \mathrm{~m}^{-3}\right)$ and $(\boldsymbol{D})$ surface

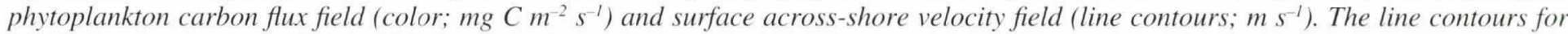
(A) density range from 23.6 to 25.4 by intervals of 0.2 , (B) euphotic zone depth range from 40 to $180 \mathrm{~m}$ by intervals of $10,(\boldsymbol{C})$ surface phytoplankton carbon range from 25 to $175 \mathrm{mg} \mathrm{C} \mathrm{m}^{-3}$ by intervals of 25 and (D) surface across-shore velocity field range from -0.7 to $0.9 \mathrm{~m} \mathrm{~s}^{-1}$ by intervals of 0.1. Upwelling and downwelling velocities $(\boldsymbol{A})$ with magnitudes greater than $11 \times 10^{-5} \mathrm{~m} \mathrm{~s}^{-1}$ are shown in dark red and dark blue, respectively. The euphotic zone depth $(\boldsymbol{B})$ is defined as the depth at which PAR values are $1 \%$ of that calculated at the surface. Red colors $(\boldsymbol{C}$ and $\boldsymbol{D})$ indicate regions of offshore carbon flux. Dark blue colors indicate regions of onshore carbon flux.

mass observed to exist $\approx 200 \mathrm{~km}$ offshore in the southern region of the CTZ (Chelton et al., 1982).

\section{References}

Chelton, D.B., P.A. Bernal and J.A. McGowan, 1982: Large-scale interannual physical and biological interaction in the California Current J. Mar. Res., 40, 1095-1125.

Haidvogel, D.B., A. Beckmann and K.S. Hedström, 1991a: Dynamical simulations of filament formation and evolution in the Coastal Transition Zone, J. Geophys. Res., 96, 1501715040 .

, J. Wilkin and R.E. Young, 1991b: A semi-spectral primitive equation ocean circulation model using vertical sigma and orthogonal curvilinear coordinates, J. Comp. Phys., 94, 151-185.

Moisan, J., 1993: Modeling nutrient and plankton processes in the California Coastal Transi- tion Zone. Ph.D. thesis, Old Dominion University, Norfolk, VA, $214 \mathrm{pp}$.

Sathyendranath, S. and T. Platt, 1988: The spectral irradiance field at the surface and in the interior of the ocean: A model for applications in oceanography and remote sensing, $J$. Geophys. Res., 95, 9270-9280.

Strub, P.T., P.M. Kosro, A. Huyer, and the CTZ Collaborators, 1991: The nature of the cold filaments in the California Current system, $J$. Geophys. Res., 96, 14743-14768. 口 